\title{
Occupational health risks of pathologists - results from a nationwide online questionnaire in Switzerland
}

Florian Rudolf Fritzsche ${ }^{1,2^{*}}$, Constanze Ramach ${ }^{3}$, Davide Soldini ${ }^{2}$, Rosmarie Caduff ${ }^{2}$, Marianne Tinguely ${ }^{2}$, Estelle Cassoly ${ }^{2}$, Holger Moch ${ }^{2}$ and Antony Stewart ${ }^{1}$

\begin{abstract}
Background: Pathologists are highly trained medical professionals who play an essential part in the diagnosis and therapy planning of malignancies and inflammatory diseases. Their work is associated with potential health hazards including injuries involving infectious human tissue, chemicals which are assumed to be carcinogenic or long periods of microscope and computer work. This study aimed to provide the first comprehensive assessment of the health situation of pathologists in Switzerland.

Methods: Pathologists in Switzerland were contacted via the Swiss Society of Pathologists and asked to answer an ethically approved, online anonymous questionnaire comprising 48 questions on occupational health problems, workplace characteristics and health behaviour.

Results: 163 pathologists participated in the study. Forty percent of pathologists reported musculoskeletal problems in the previous month. The overall prevalence was $76 \%$. Almost $90 \%$ of pathologists had visual refraction errors, mainly myopia. 83\% of pathologists had experienced occupational injuries, mostly cutting injuries, in their professional career; more than one fifth of participants reported cutting injuries in the last year. However, long lasting injuries and infectious diseases were rare. Depression and burnout affected every eighth pathologist. The prevalence of smoking was substantially below that of the general Swiss population.

Conclusions: The results of this study suggest that more care should be taken in technical and personal protective measures, ergonomic workplace optimisation and reduction of work overload and work inefficiencies. Despite the described health risks, Swiss pathologists were optimistic about their future and their working situation. The high rate of ametropia and psychological problems warrants further study.
\end{abstract}

Keywords: Occupational, Health risk, Pathologist, Musculoskeletal, Injury, Questionnaire

\section{Background}

The UK Royal College of Pathologists describes pathology as a hidden science that helps doctors to make decisions and save lives [1]. Pathology is sometimes regarded as a "hidden science", arising from a public misconception that the work of pathologists exclusively involves performing autopsies, which misses the more important tasks of diagnosing and characterising tumours

\footnotetext{
* Correspondence: Florian.Fritzsche@patho.ch

${ }^{1}$ Faculty of Health, Staffordshire University, Stoke on Trent, United Kingdom ${ }^{2}$ Institute of Surgical Pathology, University Hospital Zurich, Zurich CH-8091, Switzerland

Full list of author information is available at the end of the article
}

and infectious diseases in living patients. Numerous potential health hazards are associated with the routine work of pathologists, but publications on this topic are rare and often decades old [2-11]. While pathologists might feel hidden and neglected by the general public, they themselves may neglect the health risks associated with their own work.

Harrington and colleagues analysed causes of death of pathologists in the United Kingdom from the 1950s until the late 1980s [4-6]. They found excess death rates due to suicide and also higher rates of brain tumours and haematopoietic and lymphatic malignancies. Among the hypothetical causes of these findings was exposure to

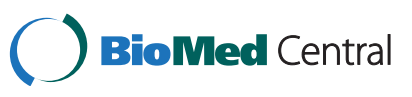


formaldehyde, a toxic, irritant and possibly carcinogenic substance. Formaldehyde is widely used in a watery solution called formalin in pathology laboratories worldwide for the fixation of human tissues [10,12-14]. Data on the association between formaldehyde exposure and cancer are not consistent, however reported malignancies include brain tumours, lympho-haematopoietic neoplasms, nasopharyngeal and pancreatic cancers [13,15-19]. Exposure to formaldehyde can also cause allergies and irritative reactions, often acquired by an occupational exposure to formaldehyde releasers like liquid soaps or detergents [20].

Biohazards are another intrinsic health risk for pathologists due to their work with potentially infective fresh human tissues during organ dissection, operative frozen section and autopsy $[21,22]$. While there is risk of human immunodeficiency virus (HIV) and hepatitis C (HCV) transmission, reported cases are very rare [23-25]. Working in close proximity to infectious aerosols, contact with tubercle bacilli, needle puncture and cutting injuries are other possible sources of infection [11,26-28].

Personal protective gear, including vision shields, protective glasses, particulate filter respirators and thin Kevlar enhanced cut-resistant protective gloves are available and highly effective. Kevlar enhanced gloves have been shown to effectively prevent cutting injuries, but compliance in wearing these gloves is relatively poor [9,29-32].

A publication by George [3] and the related reply [33] elucidate another well known but often neglected health problem in pathology laboratories[3,33]. The daily routine work of pathologists includes several hours of microscope and computer work [3]. Microscopes are often not ergonomically optimized and do not allow a neutral sitting position, requiring the pathologist to bend forward [3,8,34]. A survey among 244 cytotechnologists, a typical example of microscope-using employees, demonstrated that more than $80 \%$ of participants suffered from musculoskeletal discomfort including headache, neck pain, stiffness, back pain and upper-extremity discomfort [35]. Interestingly, less than one third of cytotechnologists reported having an ergonomic assessment of their workplace. Thompson et al. concluded that basic ergonomic training and use of ergonomic aids could substantially reduce musculoskeletal discomfort [35]. Unfortunately recommendations for such workplaces by the Centers for Disease Control and Prevention (CDC), modified by George, do not appear to match real life working situations [3]. In 2010 Flavin et al. reported similar symptoms and results including eye fatigue from microscopic work in an Irish cohort of pathologists and cytologists [2].

The problem of workplace-related musculoskeletal problems of pathologists is not new [3]. Publications from Finland and Austria have provided images of sitting postures at microscopes from 2002, 2003 and 2010 as well as potential solutions for corresponding musculoskeletal problems that illustrate these issues $[3,8,34]$. The additional suggested positive effects of ergonomic principles and ergonomic interventions at workplaces include improved morale and productivity [36,37].

In this study, occupational health risks of pathologists in a multilingual European country are systematically analysed and subsequently discussed in relation to the literature.

\section{Methods}

\section{Study design}

This study was based on an anonymous online questionnaire comprising 48 questions. Separate versions of the questionnaire were available for the three main national languages of Switzerland: German, French and Italian (see Additional file 1). The online survey resource Q-set. de (http://en.q-set.de/, Goldecker LLC, Orhalm, Germany) was used as an online platform for the questionnaires. Access to the questionnaires was only possible after completion of an informed consent form. The informed consent form was electronically submitted and could not be connected to a corresponding questionnaire. The study was approved by the cantonal ethical committee Zurich (KEK-ZH-Nr. 2011-0054/0) and by the ethical committee at Staffordshire University.

\section{Participant selection}

The study aimed to include all pathologists currently working in Switzerland, including residents in pathology. Potential participants were approached by email, via the Swiss Society of Pathologists (SSP, http://www.sgpath.ch/ infos.html). The SSP sent short information emails with the links to the consent form for all three variants of the questionnaire to members of the SSP and to all other pathologists in Switzerland for whom the SSP held contact data. For larger institutes of pathology, the email was sent to head physicians with the request to send it also to their medical employees. After 6 weeks, a reminder mail was send by the SSP. This procedure was intended to reach more than $90 \%$ of pathologists and residents in pathology in Switzerland. The total number of these was estimated to be between 250 and 300 (personal unpublished communications with the secretary of the SSP).

Participation was rewarded with optional participation in a raffle to win a Scandinavian designed ergonomically optimized office chair (Capisco Puls, HÅG Scandinavian Business Seating AS, Oslo, Norway).

\section{Rationale}

The chosen methodology relies on four main assumptions. First, a study requiring the physical attendance or visits to personnel was not practical. Second, computer and internet access were essential prerequisites for the 
work of pathologists. The SSP provided contact data and coverage of Swiss pathologists was thereby maximised. Third, unlike interviews, the online questionnaire provided anonymity while ensuring informed consent. Fourth, the chosen methodology was cost-effective; the raffle and the official SSP support were motivating factors for participation.

\section{Statistical analyses and data screening}

Statistical analysis was performed using IBM SPSS Statistics 19.0 (IBM, Armonk, NY, USA). In terms of sample size calculation, the target sample size was the whole community of Swiss pathologists. The final sample size of 163 pathologists was above the suggested sample size for an estimated whole population of 250 or 275 pathologists but just below that for an estimated population of 300 pathologists.

Kolmogorov-Smirnov tests indicated a non-normal distribution. Transformation did not normalise the data, so nonparametric techniques were used. Missing value analyses showed that with the exception of two open questions ("reasons for the personal estimation on the future relevance of pathology" and "general comments on the questionnaire"), missing values were below $10 \%$ and with the exception of 6 parameters below 5\%. Descriptive statistics, frequency analyses, Chi-squaretests, Fisher's-exact-tests, logistic regression and bivariate correlations (Spearman) were applied.

\section{Results}

\section{Participation}

163 pathologists answered the questionnaire. This corresponds to an uptake of $54 \%-65 \%$ by the $250-300$ pathologists in Switzerland. Further details on cohort characteristics are summarized in Table 1. The German, French and Italian version of the questionnaire was used by $71.8 \%, 21.5 \%$ and $6.7 \%$ of participants respectively. Since many pathologists in Switzerland are multilingual, the language chosen did not represent any specific part of the country.

\section{Health conditions}

Table 2 summarizes results on the reported health problems of pathologists in Switzerland.

\section{Musculoskeletal problems}

Musculoskeletal problems affected more than three quarters of Swiss pathologists with more than $40 \%$ of pathologists having suffered from these problems during the past four weeks. Seven percent of pathologists had been on sick leave due to musculoskeletal problems during the last year for a median of $4($ mean $=6)$ days. For the overall prevalence of musculoskeletal problems, logistic regression analysis suggested a higher risk for female pathologists $(\mathrm{p}=0.024$, effect coefficient $(\mathrm{EC})$ : 0.282 ), more weekly working hours ( $\mathrm{p}=0.023$, EC: 2.489 ) and surprisingly, fewer hours spent at the computer $(p=0.033$, EC: 0.801$)$. Regression analysis for the onemonth prevalence of musculoskeletal problems did not indicate any significant explanatory factor. Impossibility of a straight line of sight (microscopes with extensive adjustability of tubes and oculars to obtain a straight line of sight through the oculars of the microscope without the need to bend forward) was the factor closest to reaching significance ( $\mathrm{p}=0.097$, EC: 2.235 ).

The most common locations for musculoskeletal problems were neck and shoulders (Figure 1). Other locations and problems included hip, face/head, ankles and a so called "pathologists' hump" (allegedly related to microscope work).

The prevalence overall, or in the last month, of musculoskeletal problems was no lower among those with ergonomically optimized chairs (Figure 2) than among those without them. However, the majority of pathologists who used ergonomically optimized office chairs felt their symptoms were alleviated by the chairs (Figure 3 ). More than $60 \%$ of pathologists reported alleviation of their musculoskeletal problems by the use of an ergonomically optimized microscope (Figure $2 \& 3$ ). There were no statistically significant differences between different microscope manufacturers. Neither the habit of regular breaks for stretching exercises, hours spent working at the microscope or at the computer, work experience, adjustability of the microscope tube or ability of horizontal line of sight, desk characteristics, participation in sport nor presence or absence of workplace ergonomics introductions were significantly associated with the overall or one-month prevalence of musculoskeletal problems.

\section{Visual problems}

The prevalence of ametropia, defined as any kind of refractive error of the eyes, was very high in this occupational group (90\%). Myopia was the most common type of ametropia affecting about $75 \%$ of pathologists and constituting almost $85 \%$ of all vision defects (Figure 4). More than $80 \%$ of the affected pathologists had a visual impairment already before they have started working in pathology. More than 50\% of ametropic pathologists had experienced an aggravation of ametropia during their work in pathology with a median aggravation of 1.5 dioptres.

\section{Injuries}

One-hundred and thirty-five pathologists (82.8\%) reported at least one injury during their career in pathology. Injury characteristics are shown in Figure 5. One- 
Table 1 General cohort characteristics of pathologists in Switzerland

\begin{tabular}{|c|c|c|c|}
\hline Parameter & Number (\%) & Parameter & Number (\%) \\
\hline Gender & & Current position & \\
\hline Women & $89(54.6 \%)$ & Resident & $41(25.2 \%)$ \\
\hline Men & $73(44.8 \%)$ & Consultant & $121(74.2 \%)$ \\
\hline Age & & Working atmosphere & \\
\hline $25-35$ years & $45(27.6 \%)$ & Very good & $60(37.3 \%)$ \\
\hline $36-45$ years & $56(34.4 \%)$ & Good & $75(46.6 \%)$ \\
\hline $46-55$ years & $43(26.4 \%)$ & Medium & $21(13.0 \%)$ \\
\hline$>55$ years & $19(11.7 \%)$ & Bad & $2(1.2 \%)$ \\
\hline Place of work & & Mean weekly working hours & \\
\hline Private practice & $29(17.8 \%)$ & $\leq 50 \mathrm{~h}$ & $68(41.7 \%)$ \\
\hline University hospital & $65(39.9 \%)$ & $>50 \mathrm{~h}$ & $65(39.9 \%)$ \\
\hline Non-University hospital & $68(41.7 \%)$ & $>60 \mathrm{~h}$ & $26(16.0 \%)$ \\
\hline Part time work & & Part time work specification & \\
\hline No & $119(73.0 \%)$ & $(n=43)$ & \\
\hline Yes - $\geq 80 \%$ & $25(15.3 \%)$ & Part time work only short term & $10(23.3 \%)$ \\
\hline Yes - $\geq 60 \%$ & $9(5.5 \%)$ & Part time work > 3 years (long term) & $25(58.1 \%)$ \\
\hline Yes < 60\%) & $9(5.5 \%)$ & & \\
\hline Work manageable in working time & & Work predominantly efficiently organised & \\
\hline Yes & $84(51.5 \%)$ & Yes & $104(65.0 \%)$ \\
\hline No & $71(44.8 \%)$ & No & $51(31.3 \%)$ \\
\hline Regular sports & & Estimated future relevance of pathology & \\
\hline No & $43(26.4 \%)$ & Increasing & \\
\hline Yes $>1 \times /$ week & $68(41.7 \%)$ & Remaining the same & $96(58.9 \%)$ \\
\hline Yes $1 \mathrm{x} /$ week & $33(20.2 \%)$ & Decreasing & $49(30.1 \%)$ \\
\hline Yes $>1 x /$ month & $13(8.1 \%)$ & & $17(10.4 \%)$ \\
\hline Yes $<1 x /$ month & $5(3.1 \%)$ & & \\
\hline Personal 2-year perspective & & Personal 5-year perspective & \\
\hline Very good & $51(31.3 \%)$ & Very good & $44(27.0 \%)$ \\
\hline Good & $86(52.8 \%)$ & Good & $90(55.2 \%)$ \\
\hline Rather bad & $15(9.2 \%)$ & Rather bad & $15(9.2 \%)$ \\
\hline bad & $1(0.6 \%)$ & $\mathrm{Bad}$ & $2(1.2 \%)$ \\
\hline
\end{tabular}

hundred-twenty-five of these 135 participants (93\%) reported activities and locations where injuries took place. The most common activities were macroscopic organ dissection and autopsy.

The most common types of injury were cutting injuries followed by splashes of fluids or organic materials to mucous membranes. Rare other types of injury included formalin contact to skin and mucous membranes, different types of stitches and special cutting injuries from cover glasses, knives or wires.

Pathology residents were much more often affected by injuries than consultants during the previous year (Fisher's exact test: $\mathrm{p}=0.001$ ). Interestingly pathology residents were more often using cut-resistant protective gloves (51\% versus 18\%) in comparison to consultants (Fisher's exact tests: all $\mathrm{p}<0.001$, ). Concordantly the use of cut-resistant gloves was highest in university hospitals followed by non-university hospitals, being both typical training and teaching centres. The lowest values were reported from private practices $\left(\chi^{2}=11.622, \mathrm{p}=0.003,\right)$. For more than one third of pathologists in Switzerland such gloves were not available.

Surprisingly, the prevalence of injuries during the last year, including cutting injuries, did not differ significantly between reported users and non-users of these gloves. Nonetheless, glove-users career in comparison to non-users overall (Fisher's exact test: $\mathrm{p}=0.007$ ).

\section{Formalin, allergies and other health problems}

Intolerance reactions to formalin including severe mucosal or skin irritation, mucosal inflammation, fatigue 
Table 2 Health status parameters of pathologists in Switzerland

\begin{tabular}{|c|c|c|}
\hline Characteristics & Yes (\%) & No (\%) \\
\hline Ever received an introduction into work place ergonomics & $24(14.7 \%)$ & $136(83.4 \%)$ \\
\hline Ever experienced work-related musculoskeletal problems & $123(75.5 \%)$ & $40(24.5 \%)$ \\
\hline Musculoskeletal problems in the last four weeks $(n=123)$ & $69(56.1 \%)$ & $53(43.1 \%)$ \\
\hline Signed off due musculoskeletal problems last year $(n=123)$ & $11(8.9 \%)$ & $112(91.1 \%)$ \\
\hline Doing regularly short breaks for stretching exercises & $36(22.1 \%)$ & $124(76.1 \%)$ \\
\hline Any known ametropia & $145(89.0 \%)$ & $17(10.4 \%)$ \\
\hline Aggravation of ametropia since working in pathology $(n=145)$ & $82(56.6 \%)$ & $58(40.0 \%)$ \\
\hline Eye fatigue symptoms in the last month & $90(55.2 \%)$ & $68(41.7 \%)$ \\
\hline Ever experienced occupational injuries in pathology & $135(82.8 \%)$ & $28(17.2 \%)$ \\
\hline Experienced such injuries in the last year $(n=135)$ & $37(27.4 \%)$ & $95(70.4 \%)$ \\
\hline Remaining permanent damages from such injuries $(n=135)$ & $5(3.7 \%)$ & $127(94.1 \%)$ \\
\hline Ever experienced intolerance reactions against formalin & $41(25.2 \%)$ & $118(72.4 \%)$ \\
\hline Any known allergy & $55(33.7 \%)$ & $105(64.4 \%)$ \\
\hline \multicolumn{3}{|l|}{ Since working in pathology ever diseased with... } \\
\hline Tuberculosis & $2(1.2 \%)$ & $153(93.9 \%)$ \\
\hline Positive tuberculin test only & $31(19.0 \%)$ & $119(73.0 \%)$ \\
\hline Hepatitis B & $1(0.6 \%)$ & $154(94.5 \%)$ \\
\hline Hepatitis C & $0(0.0 \%)$ & $155(95.1 \%)$ \\
\hline HIV & $0(0.0 \%)$ & $154(94.5 \%)$ \\
\hline Burnout & $14(8.6 \%)$ & $141(86.5 \%)$ \\
\hline Depression & $11(6.7 \%)$ & $144(88.3 \%)$ \\
\hline Hypertension & $11(6.7 \%)$ & $144(88.3 \%)$ \\
\hline Diabetes mellitus type ॥ & $3(1.8 \%)$ & $152(93.2 \%)$ \\
\hline Malignancies & $3(1.8 \%)$ & $149(91.4 \%)$ \\
\hline Sufficient hepatitis B immunisation & $153(93.9 \%)$ & $9(5.5 \%)$ \\
\hline Ever received BCG (tuberculosis) immunisation & $128(78.5 \%)$ & $31(19.0 \%)$ \\
\hline Smoking & $17(10.4 \%)$ & $145(89.0 \%)$ \\
\hline Cut-resistant gloves available at workplace & $99(60.7 \%)$ & $60(36.8 \%)$ \\
\hline Regular personal use of cut-resistant gloves at dissections/autopsies & $39(23.9 \%)$ & $108(66.3 \%)$ \\
\hline Extraction of air in the dissection room considered sufficient & $94(57.7 \%)$ & $66(40.5 \%)$ \\
\hline
\end{tabular}

Percentages relate to the whole cohort of 163 participants unless stated otherwise. Respective sub-set numbers are then provided in the characteristics column.

or sleep disorders were experienced by one quarter of pathologists.

In terms of allergies, $34.2 \%$ of pathologists were affected. The leading allergens were grass and pollen followed by house dust mites (Figure 6).

The most common mental and systemic diseases of pathologists were burnout, depression and arterial hypertension (Table 2). The former two were significantly associated with each other (Fisher's exact test: $\mathrm{p}=0.001$ ) and together affected almost every eighth pathologist (12.3\%). Older pathologists were at higher risk for burnout or depression (Logistic regression: $\mathrm{p}=0.024$, EC: 5.489). Arterial hypertension was more common in older pathologists $\left(\chi^{2}=12.102, \mathrm{p}=0.007\right)$ but was not associated with smoking or participation in sport.

Smoking was generally rare among pathologists. Gender and age ratios for smoking were even.
Only three malignancies were reported in this cohort. They included two germ cell tumours and one bladder cancer.

Tuberculosis was also very rare in this cohort with just two pathologists affected. Interestingly almost every fifth pathologist had a positive tuberculin test during his/her career in pathology.

Other infectious diseases were exceptional (1 hepatitis $\mathrm{B}$ case) to non-existent in this cohort, and the immunisation rate for hepatitis B (HBV) was high (94\%).

\section{Work and cohort characteristics}

Over half of the pathologists (56\%) reported working an average of more than 50 hours per week. More than half of those pathologists with $\leq 50$ hours per week were employed on a part-time basis. Thirty-nine per cent of female and twelve per cent of male pathologists were 


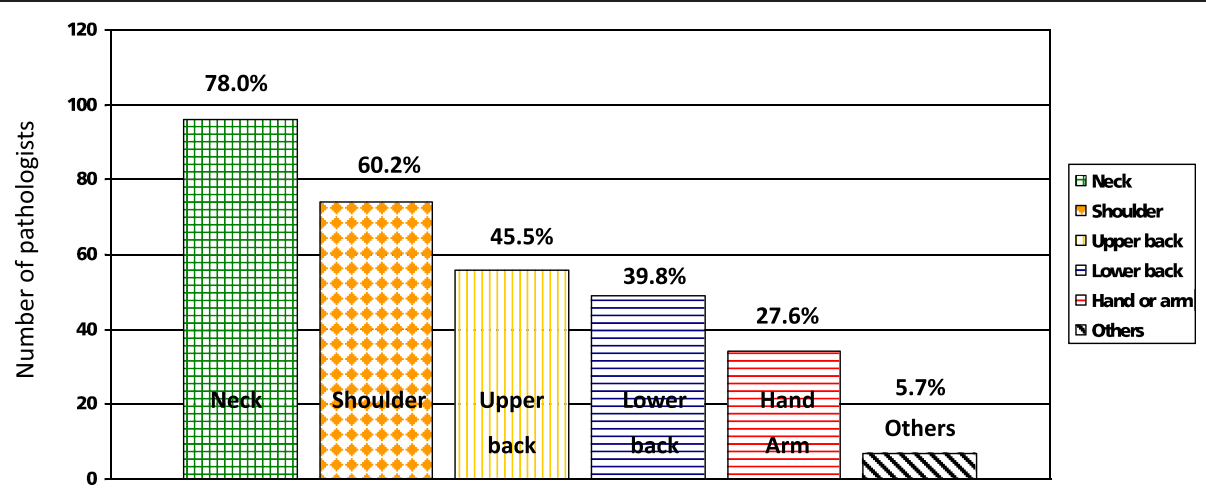

Figure 1 Location of musculoskeletal problems in Swiss pathologists. The bars reflect the number of pathologists complaining about pain in the respective location. Percentages relate to the 123 pathologists suffering from musculoskeletal problems.

part-time workers (Fisher's exact test: $\mathrm{p}<0.001$ ). More than $90 \%$ of participating pathologists used a microscope on a daily basis, and more than $95 \%$ worked daily on a computer. Median daily working hours were five and four hours for microscope and computer respectively. $35 \%$ and $26 \%$ of pathologists reported working more than 5 hours at the microscope and computer. Hours of daily microscope work were significantly correlated with work experience (Spearman bivariate correlation: $\mathrm{p}<0.001$, correlation coefficient 0.441 ) and weakly correlated with dioptres worsening during work in pathology (Spearman bivariate correlation: $\mathrm{p}=0.045$, correlation coefficient 0.235 ). More than five hours of computer work per day resulted in an adverse rating of the working atmosphere (Fisher's exact test: $\mathrm{p}=0.039$ ). Workplace characteristics are listed in Table 3.

With a market share of more than $60 \%$ of study participants, Zeiss was the most frequently reported microscope manufacturer for pathologists in Switzerland, followed by Olympus, Nikon and Leica. About 90\% of

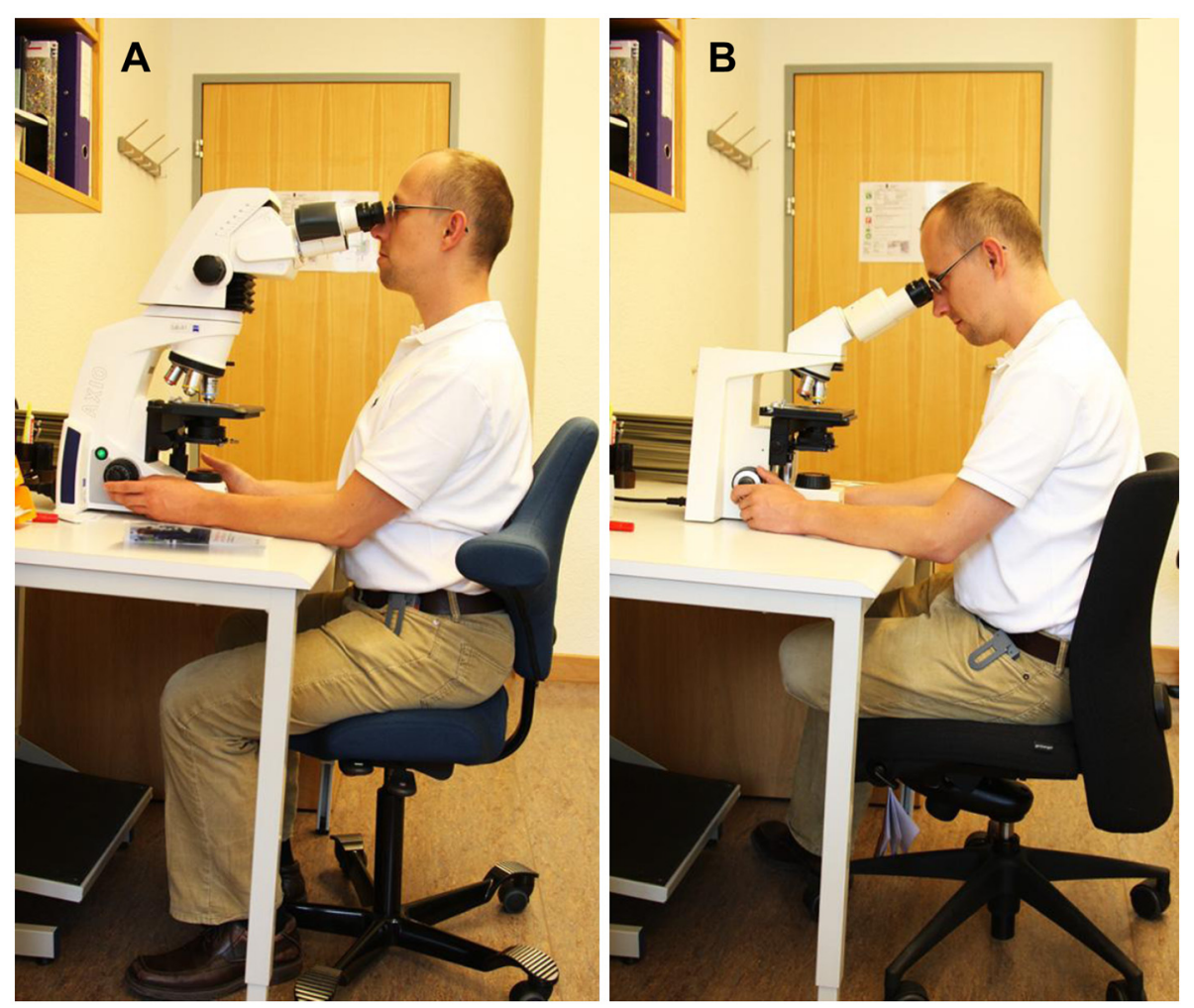

Figure 2 Ergonomically optimized and conventional microscopes and office chairs. Comparison of seating position and neutral relaxing posture between ergonomically optimized office chair ( $H A ̊ G)$ and microscope (Zeiss) (A) and a conventional office chair and microscope (B). 


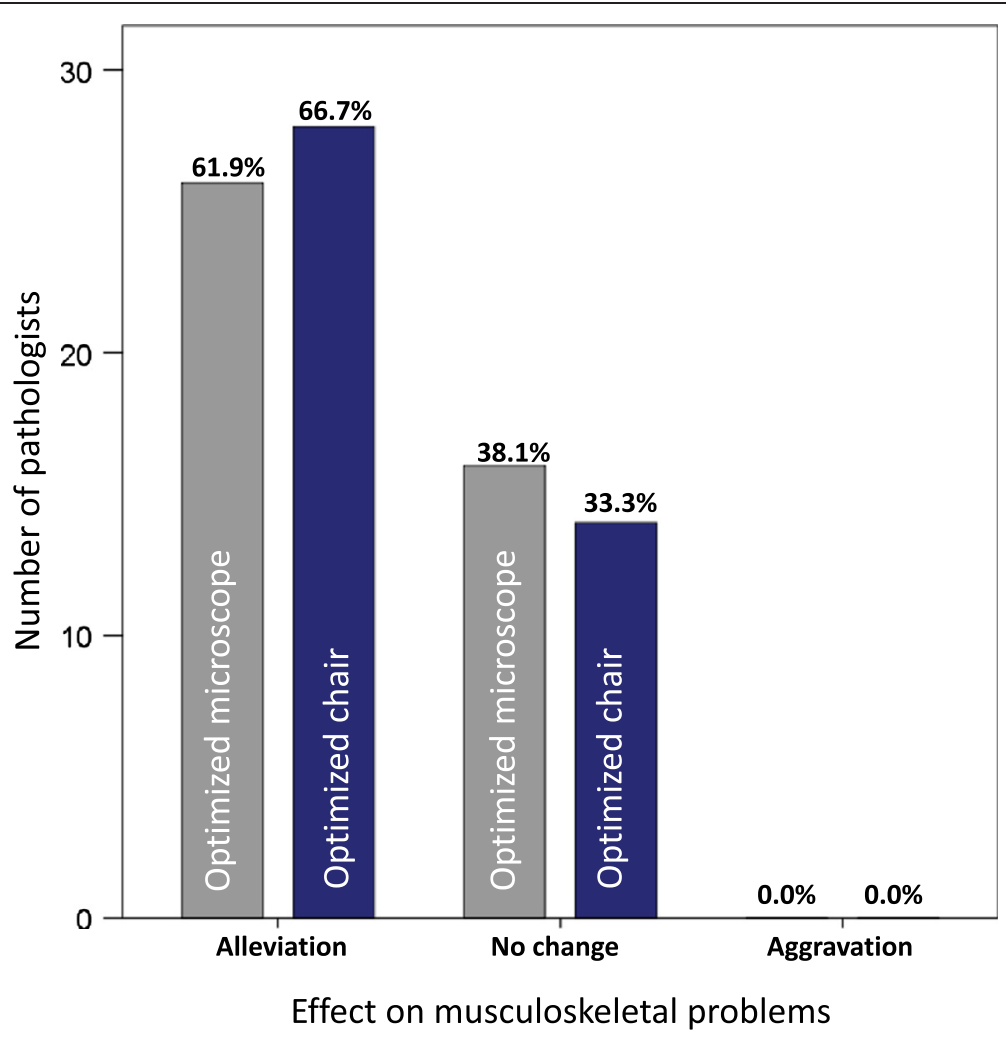

Figure 3 Effect of ergonomically optimized equipment on musculoskeletal problems. The bars reflect the number of pathologists who commented on the effect of an ergonomically optimized microscope (grey) or office chair (blue) on their musculoskeletal problems. Percentages relate to the 42 pathologists who answered this question.

Nikon and Olympus microscopes had adjustable tubes, compared to less than $50 \%$ of those manufactured by Zeiss and Leica $(x 2=24.693, \mathrm{p}<0.001)$. Similar results were found for the allowance of a horizontal line of sight $(\mathrm{x} 2=14.034, \mathrm{p}=0.007)$.

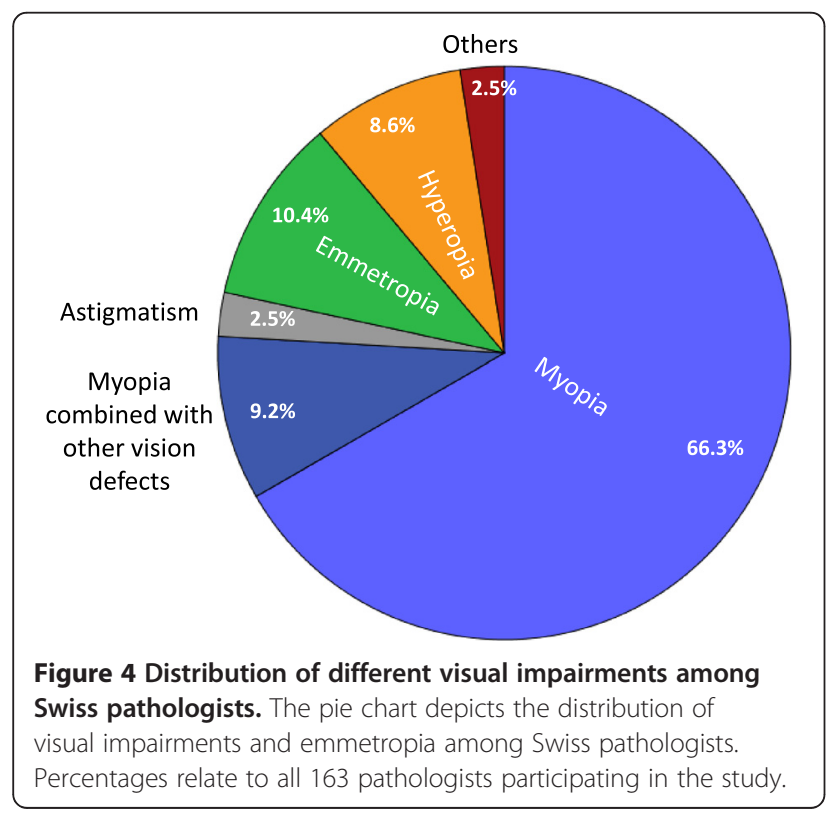

\section{Discussion}

To our knowledge, this study represents the first general health assessment of pathologists. The feedback rate of up to $65 \%$ is higher than that of most previous studies $[2,10,38]$.

The prevalence of musculoskeletal problems among pathologists was high. It is interesting to note that these problems were also experienced by many young pathologists. This argues against a mere aging effect of this disorder, and also underlines the importance of addressing this problem not only on middle aged to older employees but in the younger ones, at an early stage in their career. Musculoskeletal disorders are common in the general public and constitute one of the major causes of work absenteeism in developed countries [39-41]. Female gender, higher age and low socioeconomic status are associated factors [42]. The prevalence of upper extremity symptoms in working populations is estimated to be between $20 \%-30 \%$ [40]. While increased working hours were associated with musculoskeletal problems, other factors such as working time at the microscope/ computer or ergonomic workplace settings were not; this is in agreement with a study by Lorusso et al. [43]. The lack of an association of ergonomic workplace settings with lower prevalence of musculoskeletal problems, 


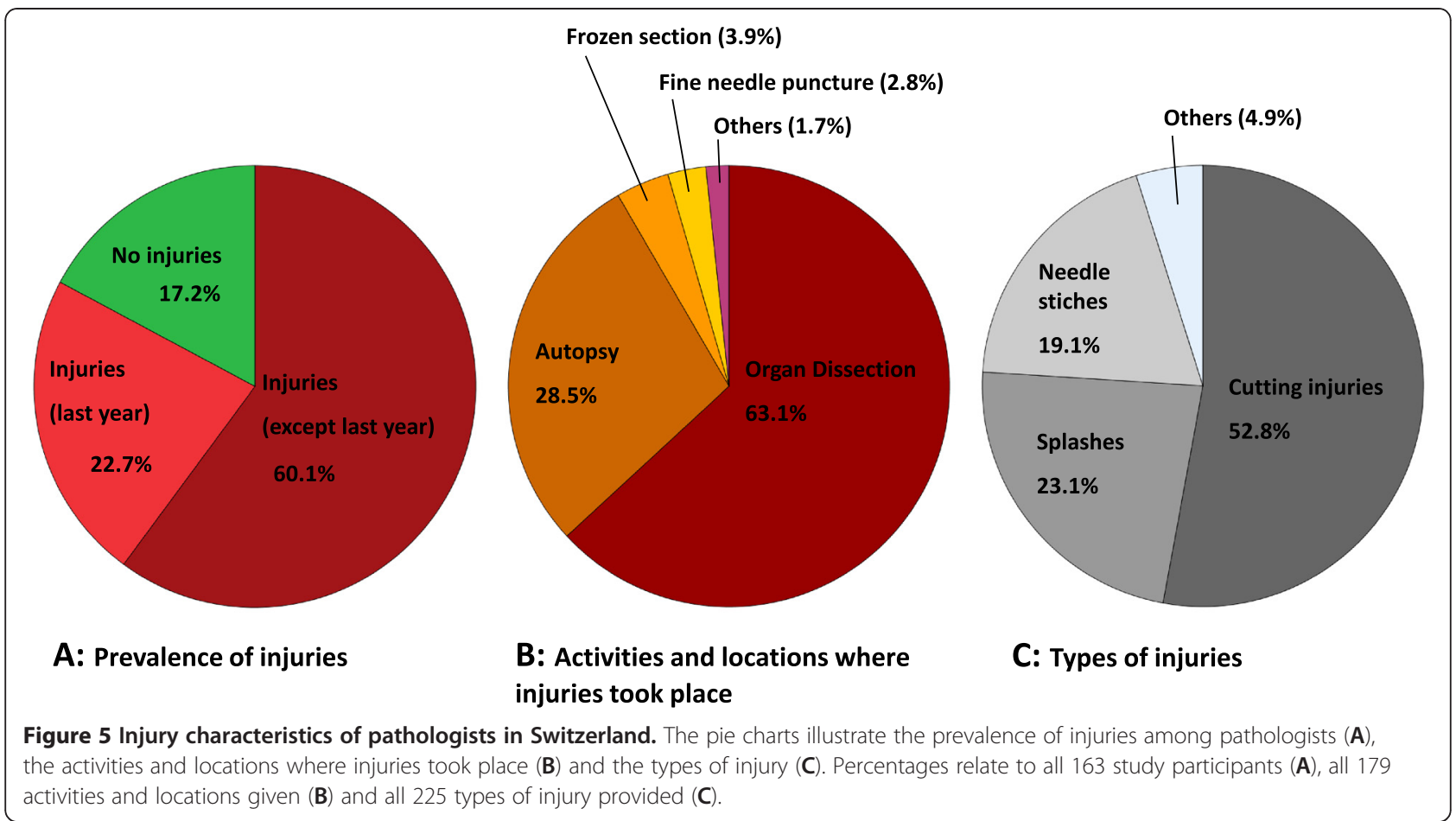

at least in terms of the one-month prevalence, is surprising. A possible explanation could be that the ergonomic equipment may have been acquired secondary to musculoskeletal disorders. Thereby the negative selection of affected pathologists might have concealed any positive effects of the ergonomic devices. The finding that $62 \%$ to $67 \%$ of pathologists with musculoskeletal problems who switched from a conventional microscope or office chair to ergonomically optimized models reported a relief of their pain further supports this theory.

Visual refractive errors are more common in pathologists than in the general population, university students or other hospital workers [44-49]. It is possible that ametropic students may choose more likely to enter this discipline. On the other hand, the work of pathologists is associated with possibly eye-straining activities such as long lasting microscopy and computer work [50-53]. The aggravation of ametropia while working in pathology, experienced by $50 \%$ of participants, might be part of the normal time course of conventional myopia, yet it may also be associated with the continuous near-field work required [54].

The analysis of injuries among pathologists suggests that injuries with sharp and possibly infectious instruments (mainly knives and needles), are almost an integral part of a pathologists' career. With about 83\% of pathologists affected, these injuries constituted the most common harm in pathology. Cutting injuries were the predominant type of injury. The predominance of residents among the injured pathologists may be explained either by their lack of experience, the training situation or by the fact that, unlike consultants, residents are more at risk as they are typically deployed on a daily basis in macroscopic organ dissection or autopsies. The few pathologists who stated having never experienced an injury in their pathology career, were mainly experienced senior consultants. With $26 \%$ of the never-injured pathologists, the use of cut-resistant gloves in this group was twice as high as in those consultants who have had experienced injuries. Seven of the eight residents who reported no injury in their pathology career $\leq 1$ year work experience. Only one of those residents reported not using cut-resistant gloves. However, given the perspective of around 4-5 years of further training, the chance for future injuries during the course of their residency should not be neglected. Recognising that the use of cut-resistant gloves was rare among elder pathologists and assuming that dexterity was not substantially different between generations of pathologists, the possibility of recall bias must taken into account when interpreting the 19 never-injured consultants. One of the elder pathologists rightly commented that some of the retrospective data should be taken "cum grano salis" (Latin: with a pinch of salt).

Cut-resistant gloves, worn between conventional vinyl gloves, can protect users from cutting injuries [29]. Loss of sensitivity and dexterity are reasons for rejection of this protective measure [29-32,55]. Splashes to mucous membranes, constituting the second most common type of injury, should be preventable by protective glasses or 


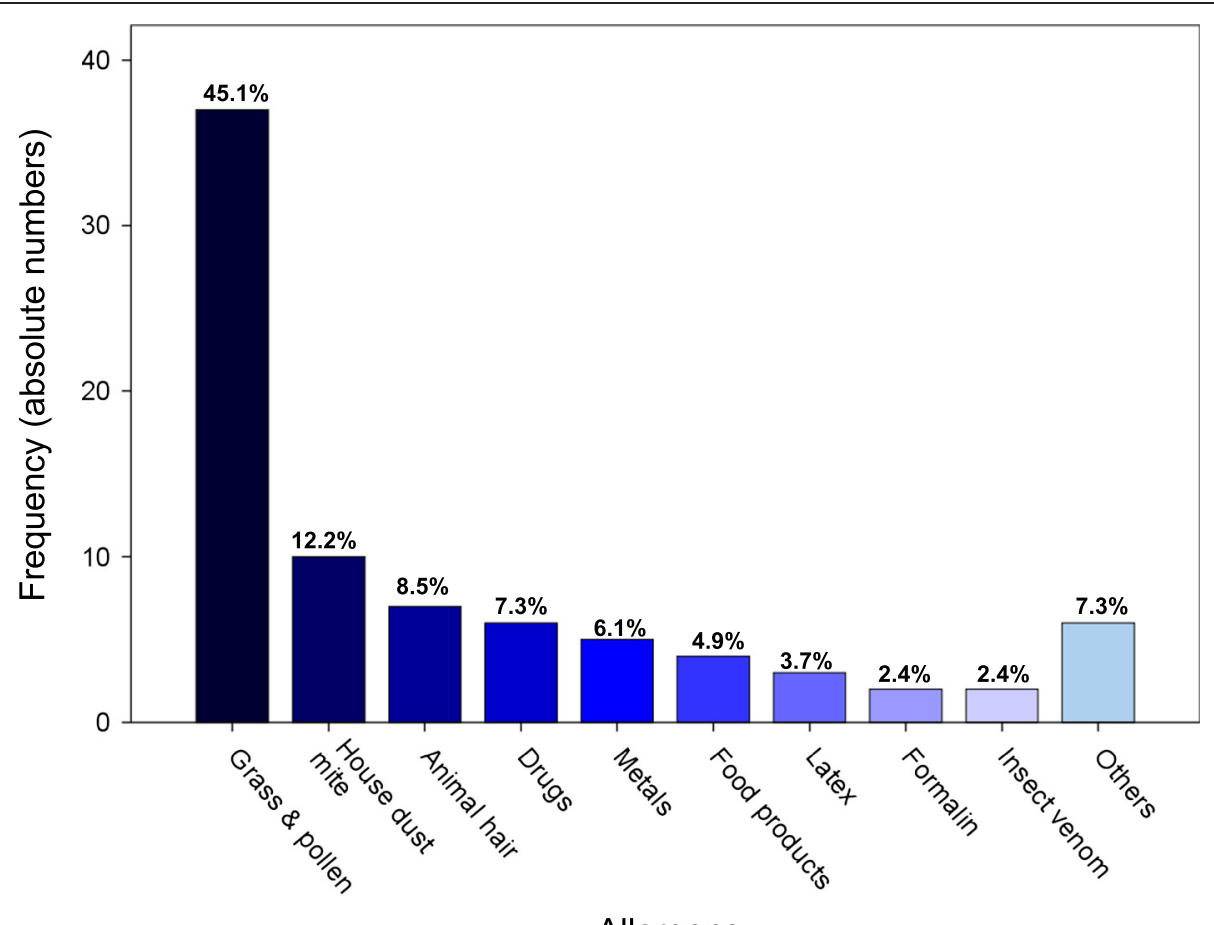

Allergens

Figure 6 Types of allergy of pathologists in Switzerland. The bars reflect the numbers of allergens reported by pathologists suffering from allergies. Grass and pollen were the most common allergen. Percentages relate to the 82 mentioned allergens in this study.

facemasks. This study did not analyse the availability or the use of such masks.

A total of $94 \%$ of those pathologists injured reported no lasting damage from these events. This finding might support the somewhat fatalistic behaviour of

Table 3 Workplace specifications and ergonomic equipment of pathologists in Switzerland

\begin{tabular}{lll}
\hline Characteristics & Yes (\%) & No (\%) \\
\hline Office & & \\
\hline At least one window & $159(97.5 \%)$ & $2(1.2 \%)$ \\
\hline Air conditioning & $36(22.1 \%)$ & $122(74.8 \%)$ \\
\hline Shared with colleagues & $54(33.1 \%)$ & $105(64.4 \%)$ \\
\hline Microscope & & \\
\hline Tube adjustable in height & $95(58.3 \%)$ & $65(39.9 \%)$ \\
\hline Regularly serviced & $130(79.8 \%)$ & $28(17.2 \%)$ \\
\hline Allows horizontal line of sight & $99(60.7 \%)$ & $61(37.4 \%)$ \\
\hline Office chair & $149(91.4 \%)$ & $11(6.7 \%)$ \\
\hline Individually adjustable & $66(40.5 \%)$ & $94(57.7 \%)$ \\
\hline Ergonomically optimised & & \\
\hline Office desk & $62(38.0 \%)$ & $99(60.7 \%)$ \\
\hline Sufficiently adjustable in height & $118(72.4 \%)$ & $43(26.4 \%)$ \\
\hline Big enough & $6(3.7 \%)$ & $155(95.1 \%)$ \\
\hline Inclination adjustable &
\end{tabular}

many consultants when rejecting cut-resistant gloves and accepting cutting injuries as an inconvenient but harmless requirement in pathology. Reports on infections resulting from such injuries are also very rare $[21,23,24]$. However the possibility of serious consequences exists, and the reduction of injuries in these high-risk fields should be given high importance.

While HBV vaccination of medical professionals is a standard precautionary measure in most developed countries, a recent study from Lithuania revealed an alarming rate of almost $90 \%$ of non-vaccinated medical staff members [56]. Meanwhile hepatitis B immunisation levels among Swiss pathologists were high. Nonetheless, about $5 \%$ of pathologists, almost exclusively senior consultants, reported being insufficiently immunized.

Formalin is the most widely used fixative in Swiss pathology institutes (unpublished personal experience). The effects of formaldehyde on human health are not well understood, especially in terms of malignancies $[13,15,57,58]$. Malignancies were very rare in Swiss pathologists. No brain tumours or lympho-haematopoietic malignancies - previously believed to be pathologyassociated malignancies - were reported [5]. Although these results argue against major carcinogenic effects of formaldehyde exposure in a pathology setting, some caution is warranted due to possible recall bias, selection bias and small numbers $[59,60]$. 
Intolerance reactions to formalin were reported by $25 \%$ of pathologists but specific allergies against formalin as well as against latex are rare [10,14]. Whether a complete abandonment of formaldehyde in pathology is reasonable and feasible will depend on further proof of adverse effects of formaldehyde, safety and economic feasibility of alternative agents and requirements of a future more molecular-based spectrum of analyses.

Smoking prevalence in Switzerland has been decreasing slowly for several years and was around 30\% in 2010, with more men smokers than women [61]. In 2007 and $200912 \%$ to $17 \%$ of Swiss primary care physicians were active smokers $[62,63]$. The prevalence in Swiss pathologists is even lower (10\%). Along with a possible trend for the desired response, the daily confrontation with fatal consequences of smoking in the morgue and in cancer diagnostics might present one possible explanation. Furthermore the smoking ban in several Swiss hospitals, bars and restaurants may also have promoted lower smoking rates.

Interestingly, burnout and depression were not rare among study participants. The burnout prevalence in other medical professions ranged from $4 \%$ to $40 \%$ depending on the degree of burnout [64-67]. In these studies high workload, more than 50 working hours per week and frequent interruptions were factors associated with burnout.

The association between work efficiency and burnout and as a trend with depression can be interpreted differently. While insufficiently organised work can be depressing, people suffering from burnout or depression might rate their surroundings, perspectives and also work efficiency as being even less satisfactory. Nonetheless, employee-centred workflow optimisation should be taken seriously, especially since almost half of pathologists were unable to finish their work within regular working hours. Nearly one third of pathologists considered the workflow in their institution to be inefficiently organised.

Tuberculosis is often considered a 'pathologists' disease' and has been demonstrated to affect pathologists much more often than the general population and other professional medical groups $[26,28,68,69]$. In comparison, the prevalence of a history of tuberculosis in our cohort was low (1.2\%). The tuberculosis skin test is considered a good test for tuberculosis control. It is also interesting that in comparison to other Swiss study cohorts a high percentage of pathologists reported having a positive tuberculin skin test during their time in pathology [70-72]. Almost $80 \%$ of pathologists had a BCG vaccination during their lifetime. Six to $10 \%$ of positive skin tests are thought to be attributable to a previous BCG vaccination but after more than 10 years after the vaccination it should no longer be considered in the interpretation of a positive test result [73,74].
According to these data, the vaccination could explain a positive skin test in 8-10 pathologists within this study. That the number is three times as high might reflect a high level of infection with tubercle bacilli, which might remain in the body in an inactive state. Therefore the notion that pathologists are at increased risk of tuberculosis infection cannot be ignored. This underlines the importance of routine precautionary measures such as effective respirator masks.

Another important finding of this study is that pathologists are generally very positive about their working atmosphere, personal work-related future perspectives and the future relevance of pathology as a medical discipline. Reasons for a positive rating of the future relevance of pathology included the relevance of pathology to medicine and especially for oncologic therapy planning, the individualisation of therapies with the need for very specific pathologic diagnoses and the future importance of molecular pathology to answer prognostic and predictive questions. Reasons for a decreasing relevance of pathology included performing fewer autopsies, the reduction of pathology in the curricula of medical students, the introduction of the DRG (diagnosis related groups) system in Switzerland and the fear that attractive diagnostic tests might be taken over by other medical disciplines.

\section{Conclusions}

This online questionnaire study is the first comprehensive occupational health assessment of a nationwide cohort of pathologists. Most pathologists in Switzerland are optimistic, long-working, physically active, normotensive non-smokers who are comfortable with their current working situation. The most common health problems include cutting injuries, ametropia, eye fatigue symptoms and musculoskeletal disorders. Formaldehyde intolerance symptoms, burnout and depression are also common. In terms of preventive actions, effective personal protective measures to reduce injuries, a further reduction in formaldehyde exposure, ergonomic improvements of pathologists' workplaces and evaluation of work processes to improve efficiency are recommended.

\section{Consent}

Written informed consent was obtained from the person pictured in Figure 2 for publication of these images. A copy of the written consent is available for review by the Series Editor of this journal.

\section{Additional file}

Additional file 1: Questionnaire: English version of the questionnaire. 


\section{Abbreviations}

BCG: Bacille Calmette-Guerin; CDC: Centers for Disease Control; DRG: Diagnosis Related Groups; EC: Effect coefficient; HIV: Human immunodeficiency virus; HBV: Hepatitis B virus; HCV: Hepatitis C virus; SSP: Swiss Society of Pathology.

\section{Competing interests}

The authors declare that they have no competing interests.

\section{Authors' contributions}

FRF conceived and conducted the study and wrote the manuscript. CR produced the French version of the questionnaire and supported its evaluation. DS created the Italian version of the questionnaire and supported its evaluation. RC and HM supervised the study from the pathological and administrative perspective. EC and MT supported the production of the French questionnaire and assisted in the application to the ethical committee in Zurich. AS was University supervisor for the study, provided support in terms of content and logistics, statistical analysis and manuscript conception. All authors read and approved the manuscript.

\section{Acknowledgements}

We are very grateful to Dr. Pierre -André Diener from the Swiss Society of pathologists for his logistic support of this study. We thank Dr. Peter K. Bode for image assistance and Mr. René Baumann from MoMoll for financial support.

The study was supported by unrestricted research funds of the University of Zurich. The ergonomic office chair was sponsored by MoMoll (MoMoll LLC, Othmarsingen, Switzerland). No other financial resources were used.

\section{Author details}

${ }^{1}$ Faculty of Health, Staffordshire University, Stoke on Trent, United Kingdom. ${ }^{2}$ Institute of Surgical Pathology, University Hospital Zurich, Zurich $\mathrm{CH}-8091$, Switzerland. ${ }^{3}$ Institute of Pathology, Cantonal Hospital St. Gallen, St. Gallen, Switzerland

Received: 28 September 2012 Accepted: 3 December 2012 Published: 6 December 2012

\section{References}

1. Pathology: the hidden science that saves lives - what is pathology? http://www.rcpath.org/index.asp?PagelD=603.

2. Flavin RJ, Guerin M, O'Briain DS: Occupational problems with microscopy in the pathology laboratory. Virchows Arch 2010, 457(4):509-511.

3. George E: Occupational hazard for pathologists: microscope use and musculoskeletal disorders. Am J Clin Pathol 2010, 133(4):543-548.

4. Hall A, Harrington JM, Aw TC: Mortality study of British pathologists. Am J Ind Med 1991, 20(1):83-89.

5. Harrington JM, Oakes D: Mortality study of British pathologists 1974-80. Br J Ind Med 1984, 41(2):188-191.

6. Harrington JM, Shannon HS: Mortality study of pathologists and medical laboratory technicians. Br Med J 1975, 4(5992):329-332.

7. Johnson MD, Schaffner W, Atkinson J, Pierce MA: Autopsy risk and acquisition of human immunodeficiency virus infection: a case report and reappraisal. Arch Pathol Lab Med 1997, 121(1):64-66.

8. Kofler M, Kreczy A, Gschwendtner A: "Occupational backache" - surface electromyography demonstrates the advantage of an ergonomic versus a standard microscope workstation. Eur J Appl Physiol 2002, 86(6):492-497.

9. Kubiczek P, Langona M, Mellen PF: Occupational injuries in a pathology residency program. Arch Pathol Lab Med 2006, 130(2):146-147.

10. Salkie ML: The prevalence of atopy and hypersensitivity to formaldehyde in pathologists. Arch Pathol Lab Med 1991, 115(6):614-616.

11. Weston J, Locker G: Frequency of glove puncture in the post mortem room. J Clin Pathol 1992, 45(2):177-178.

12. Hammer N, Loffler S, Feja C, Bechmann I, Steinke H: Substitution of formaldehyde in gross anatomy is possible. J Natl Cancer Inst 2011, 103(7):610-611.

13. National-Toxicology-Program: Final report on carcinogens background document for formaldehyde. Rep Carcinog Backgr Doc 2010, (10-5981):i-512.

14. Salkie ML: Allergens in the workplace. Clin Biochem 1994, 27(2):81-85.
15. Bosetti C, McLaughlin JK, Tarone RE, Pira E, La Vecchia C: Formaldehyde and cancer risk: a quantitative review of cohort studies through 2006 Ann Oncol 2008, 19(1):29-43.

16. Collins J J Esmen NA, Hall TA: A review and meta-analysis of formaldehyde exposure and pancreatic cancer. Am J Ind Med 2001, 39(3):336-345

17. Collins JJ, Lineker GA: A review and meta-analysis of formaldehyde exposure and leukemia. Regul Toxicol Pharmacol 2004, 40(2):81-91.

18. Beane Freeman LE, Blair A, Lubin JH, Stewart PA, Hayes RB, Hoover RN Hauptmann M: Mortality from lymphohematopoietic malignancies among workers in formaldehyde industries: the National Cancer Institute Cohort. J Natl Cancer Inst 2009, 101(10):751-761.

19. Hauptmann M, Stewart PA, Lubin JH, Beane Freeman LE, Hornung RW, Herrick RF, Hoover RN, Fraumeni JF Jr, Blair A, Hayes RB: Mortality from lymphohematopoietic malignancies and brain cancer among embalmers exposed to formaldehyde. J Natl Cancer Inst 2009, 101(24):1696-1708.

20. Aalto-Korte K, Kuuliala O, Suuronen K, Alanko K: Occupational contact allergy to formaldehyde and formaldehyde releasers. Contact Dermatitis 2008, 59(5):280-289.

21. Andrion A, Pira E: What's new in managing health hazards in pathology departments. Pathol Res Pract 1994, 190(12):1214-1223.

22. Burton JL: Health and safety at necropsy. J Clin Pathol 2003, 56(4):254-260.

23. Elder A, Paterson C: Sharps injuries in UK health care: a review of injury rates, viral transmission and potential efficacy of safety devices. Occup Med (Lond) 2006, 56(8):566-574.

24. Ganczak M, Boron-Kaczmarska A, Dziuba I: Pathologist and HIV-are safe autopsies possible? Pol J Pathol 2003, 54(2):143-146.

25. Nolte KB, Yoon SS: Theoretical risk for occupational blood-borne infections in forensic pathologists. Infect Control Hosp Epidemiol 2003, 24(10):772-773.

26. Lundgren $\mathrm{R}$, Norrman $\mathrm{E}$, Asberg I: Tuberculosis infection transmitted at autopsy. Tubercle 1987, 68(2):147-150

27. O'Briain DS: Patterns of occupational hand injury in pathology. The interaction of blades, needles, and the dissector's digits. Arch Pathol Lab Med 1991, 115(6):610-613.

28. Sugita M, Tsutsumi Y, Suchi M, Kasuga H, Ishiko T: Pulmonary tuberculosis. An occupational hazard for pathologists and pathology technicians in Japan. Acta Pathol Jpn 1990, 40(2):116-127.

29. Fritzsche FR, Dietel M, Weichert W, Buckendahl AC: Cut-resistant protective gloves in pathology-effective and cost-effective. Virchows Arch 2008 452(3):313-318

30. Pritt $B S$, Waters $B L$ : Cutting injuries in an academic pathology department. Arch Pathol Lab Med 2005, 129(8):1022-1026.

31. Watt AM, Patkin M, Sinnott MJ, Black RJ, Maddern GJ: Scalpel safety in the operative setting: a systematic review. Surgery 2010, 147(1):98-106.

32. Woods JA, Leslie LF, Drake DB, Edlich RF: Effect of puncture resistant surgical gloves, finger guards, and glove liners on cutaneous sensibility and surgical psychomotor skills. J Biomed Mater Res 1996, 33(1):47-51.

33. Waisman J, George E: More on occupational hazards for pathologists. Am J Clin Pathol 2010, 134(5):850.

34. Sillanpaa J, Nyberg M, Laippala P: A new table for work with a microscope, a solution to ergonomic problems. Appl Ergon 2003, 34(6):621-628.

35. Thompson SK, Mason E, Dukes S: Ergonomics and cytotechnologists: reported musculoskeletal discomfort. Diagn Cytopathol 2003, 29(6):364-367.

36. Kilroy N, Dockrell S: Ergonomic intervention: its effect on working posture and musculoskeletal symptoms in female biomedical scientists Br J Biomed Sci 2000, 57(3):199-206.

37. Stobbe TJ: Occupational ergonomics and injury prevention. Occup Med 1996, 11(3):531-543

38. Sawai T, Uzuki M, Kamataki A, Tofukuji I: The state of telepathology in Japan Inform: J Pathol; 2010:1.

39. Jordan K, Clarke AM, Symmons DP, Fleming D, Porcheret M, Kadam UT, Croft P: Measuring disease prevalence: a comparison of musculoskeletal disease using four general practice consultation databases. $\mathrm{Br} J$ Gen Pract 2007, 57(534):7-14.

40. Punnett $\mathrm{L}$, Wegman DH: Work-related musculoskeletal disorders: the epidemiologic evidence and the debate. J Electromyogr Kinesiol 2004, 14(1):13-23. 
41. Huisstede BM, Bierma-Zeinstra SM, Koes BW, Verhaar JA: Incidence and prevalence of upper-extremity musculoskeletal disorders. A systematic appraisal of the literature. BMC Musculoskelet Disord 2006, 7:7.

42. Pueyo MJ, Suris X, Larrosa M, Auleda J, Mompart A, Brugulat P, Tresserras R, Puente ML: Importance of chronic musculoskeletal problems in the population of Catalonia (Spain): prevalence and effect on self-perceived health, activity restriction and use of health services. Gac Sanit 2011, 26(1):30-36.

43. Lorusso A, Bruno S, Caputo F, L'Abbate N: Risk factors for musculoskeletal complaints among microscope workers. G Ital Med Lav Ergon 2007 29(4):932-937.

44. Logan NS, Davies LN, Mallen EA, Gilmartin B: Ametropia and ocular biometry in a U.K. university student population. Optom Vis Sci 2005 82(4):261-266.

45. Kinge B, Midelfart A, Jacobsen G: Refractive errors among young adults and university students in Norway. Acta Ophthalmol Scand 1998, 76(6):692-695

46. Risovic DJ, Misailovic KR, Eric-Marinkovic JM, Kosanovic-Jakovic NG, Milenkovic SM, Petrovic LZ: Refractive errors and binocular dysfunctions in a population of university students. Eur J Ophthalmol 2008, 18(1):1-6.

47. Hendricks TJ, de Brabander J, Vankan-Hendricks MH, van der Horst FG, Hendrikse F, Knottnerus JA: Prevalence of habitual refractive errors and anisometropia among Dutch schoolchildren and hospital employees. Acta Ophthalmol 2009, 87(5):538-543.

48. Onal S, Toker E, Akingol Z, Arslan G, Ertan S, Turan C, Kaplan O: Refractive errors of medical students in Turkey: one year follow-up of refraction and biometry. Optom Vis Sci 2007, 84(3):175-180.

49. Feh/sichtigkeiten (Ametropia). http://www.augeninfo.de/stat_db/fehls.php.

50. Korniushina TA: Physiological mechanisms of the etiology of visual fatigue during work involving visual stress. Vestn Oftalmol 2000, 116(4):33-36.

51. Mutti DO, Zadnik K: Is computer use a risk factor for myopia? J Am Optom Assoc 1996, 67(9):521-530.

52. Rosenfield M: Computer vision syndrome: a review of ocular causes and potential treatments. Ophthalmic Physiol Opt 2011, 31(5):502-515.

53. Blehm C, Vishnu S, Khattak A, Mitra S, Yee RW: Computer vision syndrome: a review. Surv Ophthalmol 2005, 50(3):253-262.

54. Rosenfield M, Gilmartin B: Myopia and nearwork: causation or merely association? In Myopia \& Nearwork. Edited by Rosenfield M, Gilmartin B. Oxford: Butterworth-Heinemann; 1998:193-206.

55. Kelly KE, Lee KC, Tami TA: Surgical glove perforations in otolaryngology: prevention with cut-resistant gloves. Otolaryngol Head Neck Surg 1993, 108(1):91-95.

56. Gailiene $\mathrm{G}$, Cenenkiene R: Professional biological risk factors of health care workers. Medicina (Kaunas) 2009, 45(7):530-536.

57. Rhomberg LR, Bailey LA, Goodman JE, Hamade AK, Mayfield D: Is exposure to formaldehyde in air causally associated with leukemia?-A hypothesisbased weight-of-evidence analysis. Crit Rev Toxicol 2011, 41(7):555-621.

58. Golden R: Identifying an indoor air exposure limit for formaldehyde considering both irritation and cancer hazards. Crit Rev Toxicol 2011, 41(8):672-721.

59. Beaglehole R, Bonita R, Kjellström T: Types of study. In Basic epidemiology. Geneva: World Health Organization; 1993:29-51.

60. Donaldson LJ, Donaldson RJ: Approaches to Investigation, Essential public health. 2nd edition. Oxford: Radcliffe Publishing; 2006:35-100.

61. Keller R, Radtke T, Krebs H, Hornung R: Tobacco consumption of the Swiss Population between 2001-2010, Volume 2011. Zurich: Psychologisches Institut der Universität Zürich, Sozial- und Gesundheitspsychologie; 2011.

62. Jacot Sadowski I, Ruffieux C, Cornuz J: Self-reported smoking cessation activities among Swiss primary care physicians. BMC Fam Pract 2009, 10:22.

63. Sebo P, Bouvier Gallacchi M, Goehring C, Kunzi B, Bovier PA: Use of tobacco and alcohol by Swiss primary care physicians: a cross-sectional survey. BMC Publ Health 2007, 7:5.

64. Arigoni F, Bovier PA, Sappino AP: Trend of burnout among Swiss doctors. Swiss Med Wkly 2010, 140:w13070.

65. Businger A, Stefenelli U, Guller U: Prevalence of burnout among surgical residents and surgeons in Switzerland. Arch Surg 2010, 145(10):1013-1016.

66. Arigoni F, Bovier PA, Mermillod B, Waltz P, Sappino AP: Prevalence of burnout among Swiss cancer clinicians, paediatricians and general practitioners: who are most at risk? Support Care Cancer 2009, 17(1):75-81.
67. Glasheen JJ, Misky GJ, Reid MB, Harrison RA, Sharpe B, Auerbach A: Career satisfaction and burnout in academic hospital medicine. Arch Intern Med 2011, 171(8):782-785.

68. Teppo L, Ojajarvi J, Brander E: The tuberculosis morbidity among pathologists in Finland. Scand J Respir Dis 1974, 55(5):257-261.

69. Endres R: Tuberculosis as occupational disease of physicians especially pathologists through percutaneous tuberculinization. Arztl Wochensch 1954, 9(31):736.

70. Collet E, Krahenbuhl J, Gehri M, Bissery A, Zellweger J: Risk factors for positive tuberculin skin tests among migrant and resident children in Lausanne, Switzerland. Swiss Med Wkly 2005, 10(135(47-48)):703-709.

71. Ritter C, Elger B: Prevalence of positive tuberculosis skin tests during 5 years of screening in a Swiss remand prison. Int J Tuberc Lung Dis 2012, 16:65-69.

72. Schoch O, Graf-Deuel E, Knoblauch A: Tuberculin testing of hospital personnel: large investment with little impact. Schweiz Med Wochenschr 1999, 13(129(6)):217-224.

73. Ciesielski SD: BCG vaccination and the PPD test: what the clinician needs to know. J Fam Pract 1995, 40(1):76-80.

74. Rowland K, Guthmann R, Jamieson B, Malloy D: Clinical inquiries. How should we manage a patient with a positive PPD and prior BCG vaccination? J Fam Pract 2006, 8:718-720.

doi:10.1186/1471-2458-12-1054

Cite this article as: Fritzsche et al:: Occupational health risks of pathologists - results from a nationwide online questionnaire in Switzerland. BMC Public Health 2012 12:1054.

\section{Submit your next manuscript to BioMed Central and take full advantage of:}

- Convenient online submission

- Thorough peer review

- No space constraints or color figure charges

- Immediate publication on acceptance

- Inclusion in PubMed, CAS, Scopus and Google Scholar

- Research which is freely available for redistribution

Submit your manuscript at www.biomedcentral.com/submit 